\title{
DEBATES
}

\section{Correlação de forças e recursos politicos no primeiro governo de Bachelet (2006-2010) e os impasses às possiveis inovações democráticas no Chile}

\author{
Correlation of forces and political resources in the first Bachelet \\ government and the impasses to possible democratic innovations in \\ Chile
}

\section{Kátia Alves Fukushima}

\section{Resumo}

Este artigo tem como objetivo analisar se o primeiro governo de Michelle Bachelet (2006-2010) conseguiu aprofundar a democracia chilena a partir de inovaçóes democráticas. Para tanto, a análise do governo focará em duas dimensôes: a) a correlação de forças políticas e econômicas (com a oposição partidária, setores empresariais, midiáticos e da igreja) e; b) a assimetria de recursos políticos (oriundos dos legados institucionais, do sistema político, dos pactos e da base de apoio social). A partir dessa análise, observamos que o governo de Bachelet diante da correlação de forças, bem como, da presença dos legados institucionais advindos da ditadura - como a presença de uma Constituição restritiva, do sistema eleitoral binominal e de regras rígidas para reformas - foi condicionado a manter um "governo de continuidades", não promovendo, portanto, mudanças institucionais a ponto de ampliar o espaço democrático.

\section{Palavras-chave}

Governo Bachelet; Democracia; Chile.

\section{Abstract}

This article aims to analyze if the government of Michelle Bachelet (2006-2010) managed to deepen the Chilean democracy from democratic innovations. To do so, government analysis will focus on two dimensions: a) the correlation of political and economic forces (with partisan opposition, economic, media and church sectors); b) the asymmetry of political resources (from the institutional legacies, the political system, the pacts and the social support base). From this analysis, we observe that Bachelet's government in the face of the correlation of forces, as well as the presence of the institutional legacies of the dictatorship - such as the presence of a restrictive constitution, the binomial electoral system and rigid rules for reforms - to maintain a "government of continuities", not promoting, therefore, institutional changes to the point of expanding the democratic space.

\section{Keywords}

Bachelet Government; Democracy; Chile. 


\section{Introdução}

O início do século XXI foi marcado pela ascensão de vários governos de esquerda ${ }^{1}$ na América Latina, que, embora distintos, assumiram o poder dentro das regras do jogo da democracia liberal e manifestaram, direta ou indiretamente, intençôes de promover governos mais participativos e inclusivos. A ascensão desses líderes e partidos de esquerda e centro-esquerda esteve diretamente ligada, por um lado, ao contexto econômico, marcado pela crise da "hegemonia neoliberal" e; por outro lado, pelo contexto político com a crescente crise da democracia liberal.

Tais experiências administrativas buscaram ressignificar a ideia de democracia e corroborar, em distintas escalas e graus de complexidade, para a construção de um novo projeto democrático, que tem como princípios a extensão e generalização dos direitos, a inclusão e a abertura de canais de participação com capacidades decisórias (DAGNINO, OLVERA e PANFICHI, 2006). Esses governos defenderam e/ou defendem "uma profunda transformação tanto nos horizontes normativos das sociedades latino-americanas, como das teorias que serviam de chave interpretativa na região" (CONTRERAS NATERA, 2014, p. 5).

Nesse sentido, essas esquerdas estáo ligadas exatamente a busca por inovaçóes democráticas e às práticas participativas, dando atenção a novos atores sociais até então marginalizados, como os povos indígenas e temas tão caros aos novos tempos, tais como: etnias e raça; gênero; diversidade cultural; ecologia, os quais potencializam a clássica desigualdade social (GARCIA, 2008; NATANSON, 2009).

A esquerda assumiu um papel crucial na região, à medida que esta pressupóe o aprofundamento da democracia, buscando maior igualdade, inclusão e participação, o que envolve necessariamente a transformação das relaçôes tradicionais entre Estado, Mercado e Sociedade. Contudo, como veremos, o caminho para a esquerda é muito mais complexo do que parece, principalmente, em uma região que sempre fora dominada economicamente, politicamente, socialmente e culturalmente por forças oligárquicas e conservadoras.

Neste aspecto, o caso chileno constitui um caso sui generis no que se refere a atuação da esquerda e traz algumas interrogantes: primeiro, porque a esquerda sempre

\footnotetext{
${ }^{1}$ Hugo Chávez (1999-2013) na Venezuela; Lula da Silva (2003-2010) e Dilma Rousseff (2011-2016) no Brasil; Néstor Kirchner (2003-2007) e Cristina Kirchner (2007-2015) na Argentina; Tabaré Vázquez (2005-2010; 2015-atual) e José Mujica (2010-2015) no Uruguai; Evo Morales (2005-atual) na Bolívia; Michelle Bachelet (2006-2010; 2014-2018) no Chile; Rafael Correa (2007-2017) no Equador; Daniel Ortega (2006-atual) na Nicarágua; Fernando Lugo (2008-2012) no Paraguai e; Mauricio Funes (2009-2014) em El Salvador.
} 
esteve no poder, direta ou indiretamente, desde 1990 com a restauração da democracia no país e ao longo desse período enclaves autoritários do período militar de Augusto Pinochet foram mantidos, como a Constituição de 1980 e o sistema binominal; segundo, porque a esquerda chilena, mesmo com o governo Bachelet (considerado um governo mais à esquerda dentro da sua coalizáo), manteve uma política externa pró-mercado com a assinatura de Tratados de Livre Comércio (TLC) fundado nas relaçóes bilaterais e/ou multilaterais.

A partir deste cenário, o intuito do presente artigo é analisar se o governo Michelle Bachelet, mais especificamente em seu primeiro mandato (2006-2010), conseguiu aprofundar a democracia chilena a partir de inovaçóes democráticas.

Nosso argumento é o de que a correlação de forças políticas (com a oposição partidária, setores empresariais, midiáticos e da igreja) e a assimetria dos recursos políticos (oriundos dos legados institucionais, do sistema político, dos pactos e da base de apoio social) que Bachelet enfrentou condicionou sua capacidade de implementar políticas participativas e de avançar para uma democracia mais substantiva. Em outras palavras, supomos que este governo - diante da correlação de forças, bem como da presença dos legados institucionais advindos da ditadura Constituição restritiva, sistema eleitoral binominal e regras rígidas para reformas - foi condicionado a manter o que denominamos de "governo de continuidades", náo promovendo, portanto, mudanças institucionais a ponto de ampliar o espaço democrático. A margem de manobra desse governo estava limitada tanto por aspectos institucionais do período da transiçáo democrática quanto pelos limites programáticos do pacto com a direita e da própria coalizão a qual o Partido Socialista Chileno (PS) está inserido.

Para cumprir nosso objetivo, a análise do governo Bachelet se fará a partir de duas dimensóes: a) a correlação de forças políticas e econômicas - com a oposição partidária, setores empresariais, midiáticos e setores da igreja e; b) a assimetria de recursos políticos - oriundos dos legados institucionais, do sistema político, dos pactos e da base de apoio social.

Este artigo está dividido em quatro seçôes, além desta introdução e das considerações finais. Na primeira seção, buscamos mostrar o papel da correlação de forças e dos recursos políticos no processo decisório. Na segunda seção, apresentamos a trajetória do PS e os impasses criados com a ditadura de Pinochet. Na terceira seção, discorremos sobre a Constituição de 1980, um dos limites à consolidação da democracia chilena. Na última seção, mostramos a configuração e composição do 


\section{4 | Kátia Alves Fukushima}

governo de Bachelet, demonstrando que os legados institucionais, a formaçáo de pactos e as bases sociais, bem como a relação do governo com o legislativo e com setores empresariais e midiáticos podem favorecer ou limitar o governo no processo decisório e, logo, na implementação de inovaçôes democráticas. Em seguida, tecemos as consideraçôes finais, mostrando que o governo de Bachelet se configurou em um "governo de continuidades".

\section{Correlação de forças e recursos politicos}

O fortalecimento da democracia depende da existência de um desenho institucional que ofereça oportunidades para a participação, não somente nos processos eleitorais para a escolha de representantes, mas também para uma participação cidadã no controle e na formulação de políticas públicas (HOROCHOVSKI e MEIRELLES, 2007; LISSIDINI, 2011). Portanto, a construção do desenho institucional por parte do governo irá nos mostrar se o mesmo oferece oportunidades e incentivos ao aprofundamento da democracia.

Se os governos são cruciais para o aperfeiçoamento da democracia e se os líderes de esquerdas apresentam como princípios a luta contra a desigualdade e a busca por democracias mais participativas e inclusivas, poderíamos concluir que os governos de esquerda caminharão, necessariamente, para a democracia participativa. Contudo, essa suposiçáo náo é táo simples quanto parece. Veremos que vontade política nem sempre se traduz em açóes e resultados políticos. Isto porque os recursos políticos de um governo e a correlação de forças que o mesmo se deparara, gerara diferentes oportunidades no processo decisório. Como afirma Linz (1987, p. 15), "as características estruturais das sociedades - os conflitos reais e latentes - oferecem uma série de oportunidades e obstáculos para os atores sociais e políticos, tanto homens como instituiçóes, que podem levar a um ou outro resultado".

Quando falamos de recursos políticos, estamos nos referindo ao sistema político e eleitoral onde os governos têm que atuar; aos legados institucionais - que determina os recursos institucionais e de poder - deixados por governos e/ou regimes anteriores e que influenciam no processo decisório; aos pactos estabelecidos pelos atores políticos e, às bases sociais com as quais o governo pode contar. O sistema político é o responsável pelas relaçóes entre os poderes políticos e a relação destes com a sociedade. Nele, estarão as instituiçóes com as tarefas de decidir e executar oficialmente as normas políticas práticas em que os governos e a sociedade irão atuar.

A Constituição de um país, por exemplo, como fruto de decisões legais tomadas formalmente em um momento histórico, estabelece as normas, na qual 
distintos grupos sociais podem operar (Congresso, Executivo, Tribunais). "Este poder náo se deriva do tipo de personalidades que atua no Congresso, no poder executivo ou no judicial, mas sim na relação que cada organização tem com a outra" (EASTON, 1968, p. 191, tradução nossa). Ademais, uma Constituição pode ser ampla ou restrita no que se refere à participação. Quando ampla, pode favorecer um governo no processo de aprofundamento da democracia, na medida em que apresenta sob forma de leis vários mecanismos de participação. Já quando são restritas, os governos, se de sua vontade política e se as leis para reformas forem favoráveis, terão a tarefa de mudar a Constituição ou de criar emendas buscando ampliar os mecanismos de participação.

No que se refere à correlação de forças, podemos citar a relação do governo com a oposiçáo partidária ou com setores internos ao próprio partido de governo; com os setores econômicos - empresariais e midiáticos - e até mesmo com a igreja. Um governo se depara com diferentes atores sociais e políticos com distintos interesses. "Ademais de responder as demandas de um amplo eleitorado e dos membros do partido, os governos democráticos não podem ignorar as dos grupos de interesses" (LINZ, 1987, p. 45). Muitas vezes no processo decisório é preciso calcular o custo e o benefício que determinada decisão irá gerar. Pois, quando setores chaves a exemplo dos setores econômicos - perdem a confiança no governo, "podem ser mais decisivos que o apoio do eleitorado" (LINZ, 1987, p. 45). Neste sentido, “a pressáo que se produz entre os diversos interesses, sobre o conteúdo da política prática, pode ser descrita como um 'estica e afrouxa entre os grupos' para o controle do aparato governamental” (EASTON, 1968, p. 185, tradução nossa).

As elites econômicas podem influenciar de maneira decisiva as políticas públicas e a formulação da agenda do governo. Essa influência é mais visível quando estas detêm o controle dos meios de comunicação ou quando estas podem financiar campanhas partidárias (BLOFIELD, 2006). Além da influência dos setores econômicos, a presença de setores conservadores no Congresso pode dificultar, especialmente, os governos de esquerda na implementaçáo de políticas progressistas. Já que estes setores, em geral, defendem a lógica do mercado e, logo, o interesse privado e o encolhimento do Estado.

Como veremos, a composição do governo de Bachelet, com seus respectivos recursos políticos e sua relação com os diversos interesses, ilustra as características específicas do governo e os espaços que o mesmo tivera para o aprofundamento da democracia chilena. 


\section{A trajetória do Partido Socialista Chileno (PS)}

Na década de 1930, o país possuía "um sistema constitucional firmemente estabelecido que permitia aos partidos atuar com liberdade no cenário parlamentar e no eleitoral" (ANGELL, 2009, p. 481), o que favoreceu a fundação do Partido Socialista. Assim, em 19 de abril de 1933, foi criado o Partido Socialista Chileno (PS) com a convergência de várias organizaçóes: a Nueva Acción Pública (NAP), cujas lideranças eram Eugenio Matte Hurtado, Carlos Alberto Martínez e Marmaduke Grove; a Acción Revolucionaria Socialista, dirigida por Eugenio González Rojas e Oscar Schnake; a Orden Socialista, liderada por Arturo Bianchi, e os partidos Socialista Marxista e Socialista Unificado (PS, 2004).

Desde entáo, o Partido Socialista esteve presente na vida política nacional do país, principalmente encampando a luta da classe trabalhadora. Segundo Angell (2009), o PS posicionava-se à esquerda do Partido Comunista de $\mathrm{Chile}^{2}$ (PCCh), apoiando a ocupação de fábricas e fazendas por operários e camponeses. Ao longo de sua história, o PS participou como uma das principais forças da Frente Popular ${ }^{3}$, que assumiu o governo em 1938, sob a liderança de Pedro Aguirre Cerda, do Partido Radical, bem como esteve à frente do governo da "Unidad Popular" ${ }^{4}$ (1970-1973) liderado pelo socialista Salvador Allende.

Alain Touraine (2006) mostra que o Chile passou por mudanças profundas dentro do marco institucional democrático no período que sucedeu a vitória da Frente Popular em 1938 até a superação do conservadorismo de Jorge Alessandri, pela Democracia Cristã (DC) de Eduardo Frei e, depois, pela Unidade Popular liderada por Salvador Allende. Neste período, como em nenhum outro país da América Latina, foi possível a criaçáo de um espaço de associação entre movimentos sociais de ampla dimensão e a elaboração de uma nova fórmula de governo. Neste contexto, Allende foi eleito em 04 de setembro de 1970 com 36,2\% dos votos, sendo o primeiro presidente socialista a chegar ao poder de forma democrática. Todavia,

\footnotetext{
${ }^{2}$ O Partido Comunista de Chile foi fundado em 1922.

${ }^{3}$ A "Frente Popular" era integrada pelos partidos Radical, Socialista, Comunista e Democrata.

${ }^{4}$ A "Unidad Popular" era constituída pelos partidos: PS, PCCh, MAPU (Movimiento de Acción Popular Unitaria - partido fruto de uma divisão no partido democrata cristão), Partido Radical, Acción Popular Independiente (API) e o Partido de Izquierda Radical (PIR) (PS, 2004, p. 7).
} 
esta eleição precisava da ratificação do Congresso ${ }^{5}$, para o que foi essencial um acordo com a Democracia Cristã (DC).

A proposta de Allende de implantar um socialismo por via pacífica - a "via chilena ao socialismo" -, a partir de um governo assentado sobre uma base frágil e clivada por profundas divergências políticas e ideológicas, trouxe para o Chile um cenário de incertezas. Para além de sua proposta, sua ascensão ao poder, na conjuntura da Guerra Fria, já representava o fortalecimento da posição da União Soviética no hemisfério ocidental, em contraponto à posição norte-americana já abalada pela Revolução Cubana, em 1959.

Para Moniz Bandeira (2008, p. 39), mesmo se houvesse condiçóes econômicas, sociais e políticas favoráveis ao seu projeto, a proposta de Allende "era absolutamente impensável sem a conquista da maioria parlamentar e o respaldo da maior parte da população". Nas palavras do autor, "havia um tanto de utopia no projeto de Allende". "Como promover uma revolução proletária, dentro das fronteiras nacionais do Chile, cercado por países capitalistas, a maioria dos quais sob ditaduras militares, com o suporte do capital financeiro internacional?" (MONIZ BANDEIRA, 2008, p. 100).

A fragilidade política do governo Allende, entretanto, já se colocava a partir de sua votação pouco expressiva (em torno de $30 \%$ dos votos) e da dependência de um acordo com a DC para conseguir o quórum necessário à ratificação de sua vitória pelo Congresso. Tal acordo foi firmado em outubro de 1970 através do Estatuto de Garantias Democráticas, e apesar das confabulaçóes para impedir a posse de Allende, o Congresso, em 24 de outubro de 1970, ratificou sua eleição para a presidência. Neste contexto, dentre as medidas adotadas pelo governo Allende, que desagradaram tanto seus opositores políticos quanto econômicos, estáo: a aprovação no Parlamento da nacionalização das minas de cobre; a desapropriação de 50\% das terras agrícolas, intensificando as transformaçóes rumo à reforma agrária; além da nacionalização de bancos e indústrias (CASAS, 1993). Políticas que se aproximavam de um modelo socialista ou para alguns de um "capitalismo de estado" (FIORI, 2006, p. 84).

Fiori (2006) aponta que durante todo o governo da Unidade Popular havia divergências entre os que buscavam limitar as estatizaçóes industriais aos setores

\footnotetext{
5 De acordo com a Constituição vigente (na época - a atual é de 1980), quando nenhum dos candidatos conseguisse a maioria absoluta, haveria um segundo turno entre os dois candidatos mais votados em votação indireta no Congresso.
} 
estratégicos da economia, e aqueles que defendiam estendê-las, com o intuito de gerar um novo "modo de produção", sob controle do Estado. Tais divergências culminaram na divisão da esquerda e, logo, na falta de apoio a Allende em sua própria base. Em 1972, vários conflitos eclodiram entre o governo e a oposição.

A crise de direção política, a limitada base de apoios internos insuficiente para levar a cabo a magnitude das mudanças desejadas, o distanciamento internacional promovido pelos EUA, e a conspiração civil militar frustraram radicalmente as possibilidades de êxito deste projeto (VARAS, 2012, e-book, posição 1715$)$.

Estava em trâmite a "fórmula para o caos", um conjunto de operaçôes encobertas - atentados terroristas, sabotagem, boicote econômico, deslegitimação do governo na mídia - que culminaram no golpe de Estado (MONIZ BANDEIRA, 2008). Ademais, a DC que havia garantido a ratificação da eleição de Allende, logo retirou seu apoio, fazendo com que o presidente não tivesse forças políticas para superar o conflito (TOURAINE, 2006).

Em 11 setembro de 1973, o governo Allende foi derrubado. Era o início da ditadura militar comandada pelo general Augusto Pinochet, que durou 17 anos (1974-1990), bem como do período neoliberal chileno. O Congresso Nacional foi fechado, partidos políticos dissolvidos, forças de esquerda reprimidas e os direitos humanos da populaçáo chilena pisoteados, à medida que as garantias individuais foram suspendidas (PS, 2004; ANGELL, 2009). Apesar do contexto, os socialistas começaram a reconstruir o partido e continuaram ativos na clandestinidade. Uma ala renovadora do socialismo apontava para uma moderaçáo do partido, preconizando "o planejamento democrático, a economia mista e os pactos sociais entre o governo, os trabalhadores e os empresários (a chamada Concertación Social)" (ANGELL, 2009, p. 536-537).

No processo de mobilização social contra a ditadura de Pinochet, o PS percebeu a necessidade de formar alianças e foi alcançando substantivas convergências políticas que implicou na criação da "Concertación de Partidos por la Democracia" (Concertación) em 02 de fevereiro de 1988, junto a outras forças democráticas, em especial, os partidos de centro como o democrata-cristáo e os radicais com a 
finalidade de restaurar a democracia ${ }^{6}$. A Concertación abarcou um campo ideológico bastante extenso, com o PS situado claramente à esquerda; o $\mathrm{PPD}^{7}$ na centroesquerda e a Democracia Cristã (PDC ou DC) em direção ao centro, com fraçóes situadas na centro-direita. Já a oposição à Concertación era composta por um partido claramente situado na direita - a Unión Democrática Independiente (UDI) e outro situado na centro-direita - a Renovación Nacional (RN), conformando a coalizão Alianza por Chile (MOREIRA, 2009, p. 17).

No plebiscito, realizado em 5 de outubro de 1988, a Concertación obteve uma vitória, embora apertada ${ }^{8}$, significativa para impor o "Náo" à continuidade de Pinochet no poder executivo. Contudo, vale lembrar, que embora Pinochet tivesse perdido o plebiscito em 1988, o mesmo pôde ficar no poder por mais um ano através do artigo $29^{\circ}$ das disposições transitórias contido na Constituição, e estrategicamente, garantiu através de leis a continuidade de alguns "enclaves autoritários", como a instituição de senadores vitalícios e um sistema eleitoral binominal.

Como aponta Martins (2000, p. 80), o governo Pinochet buscou "preservar as bases do modelo econômico neoliberal livre das incertezas da democracia como também o de perpetuar o papel tutelar das Forças Armadas sobre a sociedade e o futuro do Estado democrático”. As únicas reformas constitucionais, que a oposição conseguiu negociar com Pinochet, no processo de transição, foram o fim da proscrição dos partidos marxistas, o aumento do número de senadores eleitos de 26 para 38 e a reduçáo do mandato do presidente eleito em 1989 de oito para quatro anos. Ao contrário das transiçôes brasileiras e argentinas, o Chile não enfrentava neste momento uma crise econômica aguda que provocasse a comoçáo de toda a sociedade, o que explica o relativo apoio que Pinochet ainda tinha perante a mesma.

Em 14 de dezembro de 1989, a principal liderança da Concertación, Patricio Aylwin (PDC), ganhou as eleiçôes presidenciais com 55,17\% dos votos. O segundo colocado Hernán Buchi Buc (UDI), ligado ao regime militar, obteve 29,4\% dos

\footnotetext{
${ }^{6}$ O Partido Comunista Chileno não fez parte da coalizão Concertación, pois defendiam a revolução armada como único meio de restaurar a democracia. Ver: Angell, 2009.

${ }^{7}$ O Partido por la Democracia (PPD) emergiu do PS e foi criado pelo socialista Ricardo Lagos como um "partido instrumental" para participar do plebiscito de 1988. O PPD também integra a Concertación, propondo uma imagem mais moderna e menos ideológica que o PS.

${ }^{8}$ De um total de 7.251.933 votos emitidos, 3.967 .569 (55,99\%) votaram a favor do "NO" (Não à continuidade de Pinochet), enquanto 3.119.110 eleitores votaram a favor do "SÍ", o que representou $44,01 \%$ do total.
} 
votos. Nas eleiçóes parlamentares, os socialistas representados através do Partido Amplio de Izquierda Socialista (PAIS) e do PPD, elegeram 19,1\% dos deputados. Já o Partido Democrata Cristáo (PDC) obteve 31,67\% de cadeiras. No total, a Concertación obteve $57,5 \%$ de cadeiras. A coalizão opositora Alianza obteve $40 \%$ das cadeiras na Câmara (DOSEK, 2010).

Do processo de redemocratizaçáo em diante o PS sempre esteve integrado a Concertación, que se manteve no poder executivo até os dias atuais com exceção do mandato de 2010-2014 que foi governado por Sebastian Piñera do partido de centrodireita - Renovação Nacional. No que se refere as eleiçóes parlamentares, a Concertación também triunfou durante todo o período. Portanto, não é possível analisar a atuação do PS sem analisar a coalizão da qual o mesmo faz parte - a Concertación, hoje, Nueva Mayoría.

Durante a luta contra a ditadura de Pinochet, a Concertación apresentava forte crítica ao modelo neoliberal, especialmente às privatizaçóes e à deterioração do equilíbrio social, e exigia mudanças drásticas, tais como a intervenção estatal e medidas para superar o desemprego e a profunda desigualdade de renda (WEYLAND, 2000). No entanto, ao assumir o poder na década de 1990, os governos concertacionistas mantiveram as principais características do modelo neoliberal.

Weyland (2000, p. 81) explica que essa medida se deve a "aversão por riscos por parte do governo e da maioria da população na nova democracia chilena”. Segundo Linz (1987, p. 56), a "experiência de um governo não democrático e o temor que produz leva a uma grande maioria de votantes a continuar dando seu apoio ao 'centro' como uma posição segura", ou seja, a opção "que melhor garante a supervivência da democracia existente, apesar de sua decepçáo com sua atuação". Qualquer força política que mostrasse uma certa radicalidade, poderia perder o apoio da população.

Ademais, na metade dos anos 80 , as políticas neoliberais deram alguns frutos, apresentando "inflaçáo baixa e equilíbrio externo e fiscal, que contrastava fortemente com a situação muito mais desesperadora dos outros países latino-americanos" (WEYLAND, 2000, p. 86), o que justificou a opção de tais governos pelo sistema de livre-mercado imposto durante a ditadura de Pinochet, embora em uma versão mais flexível. No entanto, não foi só no plano econômico que os governos da Concertación mantiveram as políticas de Pinochet, já que o Chile ainda continua sob 
a Constituição de 1980 e até 2014 mantinha o sistema eleitoral binominal ${ }^{9}$, o que assegurava à direita uma representação que não guardava relaçáo com os votos obtidos (GARRETÓN, 2012; NATANSON, 2009).

Como podemos observar, os governos concertacionistas não haviam superado os enclaves autoritários, além disso, a chegada de Pinochet no Parlamento como senador vitalício (1998-2002) demonstrava a impunidade aos militares. Até 2005, havia senadores que eram designados e não eleitos pelo voto popular. Segundo Garretón (2012, p. 92), essa institucionalidade impede "os governos de cumprir com os programas para os quais foram eleitos porque carecem de recursos materiais e políticos devido aos enclaves autoritários ou aos poderes de veto de minorias”.

Os dois primeiros governos concertacionistas foram liderados pela Democracia Cristá (PDC) - Patricio Aylwin (1990-1994) e Eduardo Frei Ruiz-Tagle (1994-2000). Tais governos, embora sem romper com os legados institucionais da ditadura, buscaram promover uma "democracia liberal inclusiva", unindo crescimento econômico com políticas redistributivas, buscando superar a pobreza (CASTELLS, 2005). Segundo Linz e Stepan (1999, p. 248), Patricio Aylwin, diante do perigo e da dificuldade de remover os enclaves autoritários, optou "por conviver com eles, como o preço a ser pago pela estabilidade e por um grau mínimo de apoio político da direita democrática aos outros itens de seu programa”.

Essa foi a mesma lógica seguida por Eduardo Frei Ruiz-Tagle. Nos programas de governo dos dois presidentes não havia propostas para mudar a Constituição, apenas propunham reformas que buscavam superar os enclaves autoritários, tais como a eliminação dos senadores designados; mudanças nas funçôes do Conselho de Seguridade Nacional (COSENA); proposta de um sistema eleitoral proporcional; modificação do Tribunal Constitucional para maior autonomia; restabelecimento das atribuiçôes do presidente no que se refere às Forças Armadas. Contudo, nenhuma dessas propostas foram encaminhadas de fato. A justificativa era a certeza que tais propostas não passariam pelo Congresso devido o poder de veto que tinha a direita (FUENTES, 2010).

A vitória de Ricardo Lagos (PPD), em 2000, parecia demonstrar, pelo menos ideologicamente, um direcionamento mais à esquerda da Concertación. Seu

\footnotetext{
9 O fim do sistema binominal chileno ocorreu no segundo mandato de Bachelet (2014-2018). A promulgação da Lei n. 20.840 de 05/05/2015 substituiu o sistema eleitoral binominal por um de caráter proporcional e inclusivo, fortalecendo desta maneira a representatividade do Congresso Nacional (CHILE, 2015).
} 
programa de governo ainda mantinha as propostas de reforma dos dois governos anteriores com o intuito de eliminar os enclaves autoritários e ainda acrescentava a proposta de reforma ao quórum alto para reforma de lei. A prisão de Pinochet em 1998, em Londres, de certa forma, favoreceu o processo de diálogo entre governo e oposição no Chile, isto porque as forças de direita buscavam se distanciar da figura de Pinochet. "Os temas em debate por parte dos principais atores ficaram limitados a um número relativamente reduzido de âmbitos constitucionais e que se referiam principalmente a redução dos enclaves autoritários" (FUENTES, 2010, p. 14).

O governo Lagos avançou com a aprovação, em 26 de agosto de 2005, de um pacote de reformas constitucionais que eliminava os senadores vitalícios e recuperava a prerrogativa de designar os chefes militares. No entanto, não houve reformas no sistema eleitoral (NATANSON, 2009, e-book, posiçáo 3228). Ademais, as reformas ocorreram de cima para baixo, sem a participação dos atores sociais. As reformas não foram suficientes e o debate em torno de novas reformas estava presente no congresso.

[...] algunos senadores del PDC y del PS [...] plantearon abiertamente la necesidad de introducir nuevos cambios constitucionales. El senador Andrés Zaldívar estimó que se requería una reforma al sistema binominal y al sistema de quórum. En tanto, el senador Carlos Ominami postuló la necesidad de crear una comisión constituyente integrada por personas que no aspiraran a cargos de elección popular, para elaborar los principios de una nueva Constitución que sería sometida a plebiscito de cara al Bicentenario (FUENTES, 2010, p. 24).

Embora o Chile tenha sido governado pela centro-esquerda desde 1990, sempre pairou uma sombra da ditadura na sociedade e no próprio governo. Ademais, é importante ressaltar o forte conservadorismo presente no país e o peso da igreja católica, o que dificulta a adoção de medidas consideradas progressistas. Tanto é verdade que, até 2004, o Chile era o único país ocidental, juntamente com a Ilha de Malta, a não permitir o divórcio ${ }^{10}$. Havia uma forte oposição da Igreja Católica à lei do divórcio, tanto que o projeto de lei ficou transitando durante nove anos no Congresso antes de ser referendado.

A cúpula da igreja fomentava campanhas publicitárias nos meios de comunicação, com o slogan "No divorciemos a Chile", que aludiam o divórcio como

${ }^{10}$ A norma até então vigente era de 1884. 
o causador de problemas de violência e drogas entre os jovens. Durante a votação no Congresso, membros de uma organização conservadora "Acción Familia” protestaram contra a lei com cartazes que diziam "O divórcio empobrece as mulheres". Por sua vez, a presidente da Câmara de deputados Isabel Allende rebateu a campanha conservadora, assinalando que "la gente no se divorcia porque existe una ley que lo permite. Se divorcia porque se acaba su relación amorosa” (QUILODRÁN, 2004, s/p). No dia 07 de maio de 2004, a lei do divórcio no Chile (Lei n. 19.947) foi promulgada.

Embora o governo Lagos tenha avançado em muitos pontos, muitos temas ficaram pendentes, como a Constituição de 1980, o sistema binominal, o sistema educacional e o sistema previdenciário.

\section{Constituição chilena de 1980: um limite à democracia}

A Constituição chilena corresponde a um elemento sui generis do atual cenário político da América Latina, demonstrando um paradoxo entre o processo de redemocratização e ascensão da centro-esquerda no poder e a manutenção de uma Constituição que fora aprovada durante o regime militar.

Sob uma fachada participativa, a Constituição foi ratificada por plebiscito $^{11}$ em 11 de setembro de 1980, de forma duvidosa e com denúncias de incongruências jurídicas, tendo o apoio de parte da direita tradicional e de setores empresariais (NEGRETTO, 2015). Ironicamente, o artigo 4 da Constituição afirma que o Chile constitui uma "República democrática", contudo, a Carta Magna na realidade representou a institucionalização do regime autoritário, fundada em concepçóes políticas e econômicas excludentes.

O exercício da soberania, expresso no artigo 5, "se realiza pelo povo através de plebiscito e de eleiçôes periódicas e, também, pelas autoridades estabelecidas por esta Constituição. Nenhum setor do povo, nem indivíduo algum pode assumir seu exercício” (CHILE, 1980). O texto constitucional só prevê a consulta popular por meio do plebiscito quando no processo de reforma constitucional houver divergência entre o Congresso Nacional e o Presidente da República (Artigo 117). Fora esse artigo não há na Constituição chilena mecanismos de democracia direta, a nível nacional como referendos, recall e muito menos iniciativa popular de lei. Logo,

\footnotetext{
11 Os resultados oficiais do plebiscito foram: votos pelo "Sim" à nova Constituição: 4.204.879 (67,04\%); pelo "Não": 1.893 .420 (30,19\%); nulos: 173.569 (2,77\%).
} 
podemos perceber que a Constituição chilena é muito restritiva quanto à participação popular.

O grande debate em torno dessa Constituição está exatamente no processo de transição da ditadura ao regime democrático. Em 1988 estava previsto no texto constitucional (Disposiçóes Transitórias $27^{\circ}$ a $29^{\circ}$ ) um outro plebiscito, o que para alguns setores de oposição ao governo Pinochet seria a esperança para o fim da ditadura, e como a história mostrou, não estavam de todo errados. $\mathrm{O}$ plebiscito estipulava pela continuidade ou não de Pinochet, que se ganhasse governaria até 1997. O resultado levou ao fim da ditadura pinochetista com 55,99\% dos votos pelo " $N O$ ". Embora derrotado no plebiscito, Pinochet ainda tinha significativo apoio na sociedade civil recebendo $44,01 \%$ dos votos a favor de sua continuidade. Juntamente com este apoio, o exército encontrava-se unido o que fortalecia ainda mais a figura de Pinochet.

Os setores opostos à ditadura de fato estavam certos em ver no plebiscito a esperança para o retorno à democracia, contudo, não foram capazes de enterrar a ditadura no passado. A estratégia do ditador antes de deixar o poder foi aprovar várias medidas conhecidas como a "legislaçáo de amarre". Assim, por meio de plebiscito, em 1989, 91\% dos eleitores aprovaram um pacote de reformas constitucionais de certa forma acordadas entre a ditadura e os opositores da época (ALTMAN, AGUERO e SALAS, 2014). Nas palavras de Martins (2000, p. 69), "a liberalização chilena foi realizada com o claro objetivo de perpetuar a ordem autoritária, e não de encontrar uma saída honrosa para ela”. Ou como afirma Linz e Stepan (1999, p. 244), “esse foi também o cenário de uma transição extremamente cerceada e da transferência de poder mais democraticamente 'desleal' entre todos os nossos casos do Sul da Europa e do Cone Sul" ${ }^{12}$.

Dentre as principais medidas adotadas por Pinochet antes de deixar o Poder Executivo e que constituíram limites à soberania democrática, podemos citar: o direito constitucional ao presidente de nomear nove dos 47 membros do Senado (Artigo 45); a continuidade da liderança militar, em que Pinochet obteve a prerrogativa da inamovibilidade ${ }^{13}$, na qualidade de chefe do exército até março de 1998 com direito a voz e voto no Conselho de Segurança Nacional (Artigos 95 e 96);

\footnotetext{
${ }^{12}$ Os casos a que Linz e Stepan se referem no Sul da Europa são Espanha, Portugal e Grécia. No Cone Sul, os autores se referem à Argentina, Uruguai, Chile e Brasil.

${ }^{13}$ Além de Pinochet, três membros da junta, pertencentes à Marinha, à Aeronáutica e à Policia tinham a prerrogativa de inamovibilidade.
} 
aumento da autonomia institucional das Forças Armadas através da Lei Constitucional Orgânica das Forças $\operatorname{Armadas}^{14}$ (Lei n. 18.948 promulgada em 22/02/1990); mudanças na regra do jogo eleitoral, com a instituiçâo do sistema binominal; leis que concediam estabilidade a grande parte dos funcionários do setor público e autonomia ao Banco Central (LINZ e STEPAN, 1999; CHILE, 1980).

A Constituição chilena com as "leis de amarre", tornou-se no grande impasse para os governos democráticos. As normas rígidas para a reforma (parcial ou total) da Constituiçãoo ${ }^{15}$ e as leis orgânicas dificultavam qualquer ação para acabar com os entraves autoritários. Uma reforma constitucional necessitaria de $60 \%$ de aprovação na Câmara e no Senado ${ }^{16}$ para ser aprovada pelo Tribunal Constitucional, organismo composto por sete membros nomeados por Pinochet, que não poderiam ser afastados até que completassem 75 anos de idade (Artigo 81) (LINZ e STEPAN, 1999). O regime de Pinochet foi capaz de impor barreiras à transição, em que os militares permaneceram "no desempenho de funçôes sancionadas pelo Estado e no controle de verbas públicas" (LINZ e STEPAN, 1999, p. 248). A consequência foi a presença de uma Constituiçáo restritiva e de uma democracia limitada, em que boa parte do aparato estatal não estava sob o controle dos governos democráticos.

\footnotetext{
14 Dentre os dispositivos contidos na Lei, o presidente não tem mais o direito de decretar a aposentadoria compulsória de oficiais; foram dadas aos militares $10 \%$ das divisas auferidas em todas as vendas de cobre (LINZ e STEPAN, 1999; CHILE, 1990).

${ }^{15}$ A exigência de altos quórum (3/5) para reformar a Constituição foram parte de uma poderosa rede amortizadora e protetora dos setores militares (VARAS, 2012).

${ }^{16}$ Como demonstram Linz e Stepan (1999), o caso dos resultados das eleiçóes de 1989 demonstram a dificuldade do governo democrático em conseguir os $60 \%$ no Senado. Na referida eleição, a Concertación fez 22 dos 38 senadores eleitos. No entanto, com os nove senadores designados, a Concertación precisaria de dois votos para atingir a maioria simples e seis votos, somando um total de 28 votos, para conseguir aprovar grandes mudanças na Constituição.
} 


\section{O primeiro governo de Bachelet (2006-2010): recursos politicos e correlação de forças}

A vitória de Bachelet e do Partido Socialista em $2006^{17}$ ascendeu uma esperança para uma nova institucionalidade no Chile, além de ter sido um fato surpreendente - a eleição de uma mulher - em uma "sociedade notoriamente machista e tradicional" (ALTMAN, 2006, p. 22).

O cenário para a governabilidade parecia positivo para a nova presidente. A Concertación obteve maioria na Câmara dos Deputados, com 65 deputados eleitos de um total de 120. Destes, o PDC elegeu 20 deputados, o PPD elegeu 21 deputados, o PS elegeu 15 deputados e o PRSD elegeu sete deputados. Essas eleiçóes demonstraram que o bloco progressista no interior da Concertación - PS, PPD e PRSD vem se constituindo na força majoritária no interior da coalizão. A oposição integrada na coalizão Alianza elegeu 54 deputados, sendo 19 pertencentes à RN, dois independentes e 33 pertencentes à UDI, partido majoritário na Câmara (Tabela 1).

Tabela 1 - Composição da Câmara por Lista/Pactos - Chile (Eleiçóes 2005)

\begin{tabular}{l|c|c|c|c}
\hline \multicolumn{1}{c|}{ Lista/Pacto } & Votos & $\%$ & Candidato & Eleito \\
\hline A.- Fuerza Regional Independiente & 77.213 & $1,17 \%$ & 23 & 1 \\
\hline B.- Concertación Democrática & 3.417 .207 & $51,76 \%$ & 120 & 65 \\
\hline C.- Juntos Podemos Más & 488.618 & $7,40 \%$ & 115 & - \\
\hline D.- Alianza & 2.556 .386 & $38,72 \%$ & 120 & 54 \\
\hline Independientes (Fora Do Pacto) & 62.387 & $0,94 \%$ & 8 & - \\
\hline Votos válidos & $\mathbf{6 . 6 0 1 . 8 1 1}$ & & 386 & 120 \\
\hline
\end{tabular}

Fonte: SERVEL, 2005.

No Senado, a Concertación também obteve maioria, elegendo 11 senadores de um total de 20 cadeiras em disputa (sendo cinco do PDC, um do PPD, quatro do PS e um do PRSD). A oposição integrada na coalizão Alianza elegeu oito senadores (sendo cinco pertencentes à UDI e três à $\mathrm{RN}$ ). Além destes, foi eleito um senador independente - fora dos pactos (Tabela 2).

\footnotetext{
${ }^{17}$ Nas eleiçóes presidenciais realizadas em 11 de dezembro de 2005, Bachelet obteve 45,96\% dos votos e o segundo candidato mais votado Sebastián Pińera (RN) obteve 25,41\%. No segundo turno realizado em 15 de janeiro de 2006, Bachelet saiu vitoriosa com 53,50\% dos votos contra 46,50\% de Sebastián Piñera (DOSEK, 2010).
} 
Tabela 2 - Composição Política do Senado (1990-2006) - Chile

\begin{tabular}{|c|c|c|c|c|c|c|}
\hline Partidos & Coalizáo & 1990 & 1994 & 1998 & 2002 & 2006 \\
\hline UDI & \multirow[b]{2}{*}{ Alianza } & 2 & 3 & 5 & 11 & 9 \\
\hline $\mathrm{RN}$ & & 13 & 11 & 7 & 7 & 8 \\
\hline UCC & & & & 1 & & \\
\hline $\mathrm{DC}$ & \multirow{5}{*}{ Concertación } & 13 & 13 & 14 & 11 & 6 \\
\hline PPD & & 1 & 2 & 2 & 2 & 3 \\
\hline PS & & 4 & 5 & 4 & 5 & 8 \\
\hline PR (PRSD*) & & 3 & 1 & & 2 & 3 \\
\hline SD & & 1 & & & & \\
\hline Independentes & & 1 & 3 & 5 & 1 & 1 \\
\hline Vitalício & & & & 2 & 1 & \\
\hline Designados & & 9 & 9 & 9 & 9 & \\
\hline Total & & 47 & 47 & 49 & 49 & 38 \\
\hline
\end{tabular}

*O PRSD corresponde a fusáo entre o PR e o SD.

Fonte: EMOL, 2009.

Com o fim dos senadores designados e vitalícios a partir da reforma constitucional de 2005, foi a primeira vez desde 1990 que a Concertación conseguiu maioria no Senado. Embora, a composição no Congresso em 2006 tenha demonstrado um cenário favorável ao governo de Bachelet, o legado institucional deixado ainda pelo regime ditatorial e não superado por seus pares nos governos anteriores constituiu os limites à sua administração.

O primeiro impasse ao governo Bachelet foi a presença da Constituição de 1980, muito restrita em diversas áreas, que apesar de algumas reformas importantes, via Congresso, realizadas até o momento, ainda colocava o governo sob um marco limitado. O quórum alto (de 3/5) exigido para reformas constitucionais e a composição no Congresso ao longo dos governos concertacionistas demonstraram que nenhuma coalizão com representação no Congresso poderia aprovar uma reforma sem contar com o acordo da outra contraparte (FUENTES, 2010). As reformas até então implementas pelos governos concertacionistas foram através da busca de consensos com as forças de direita. Estas, que em geral, apresentam forte vínculo com as elites econômicas e com o conservadorismo católico.

O sistema eleitoral chileno - sistema binominal - também se colocou como um impasse ao governo. Este sistema foi incorporado à Lei Orgânica n. 18.799 de 26 de maio de 1989. Nesse sistema, os eleitores votam por um candidato, mas o partido 
ou a coalizão acumula os votos. Cada um dos dois partidos com maior número de votos obtém uma cadeira, salvo se o partido que está na frente obtiver o dobro dos votos em relação ao segundo colocado, neste caso, o mesmo terá duas cadeiras. Há, portanto, uma sobre-representação da segunda maioria. Tal sistema favorece as forças políticas maiores e, em especial, o segundo partido ou coalizão mais importante em detrimento dos partidos pequenos (PAYNE, 2006).

Os partidos que não formam parte de uma grande coalizão veem truncadas suas possibilidades de ascender ao Congresso, já que as barreiras de entrada são muito altas. Tal é o caso do Partido Comunista, que por não fazer parte das duas coalizóes principais, não havia conseguido eleger representantes apesar de ter ao redor de $6 \%$ de votos nas eleiçóes de deputados (VARAS, 2012). Neste sentido, o sistema binominal promove um bipartidarismo ou a formação de duas coalizóes de partidos, o que é negativo para a representatividade do sistema, implicando em pouca competitividade e escassas opçóes para o cidadão (BOENINGER, 2009). O sistema binominal chileno se colocou como a base principal na formação de um sistema de vetos (poder de veto da minoria de direita) que conseguiu criar e sustentar um impasse político (GARRETÓN, 2012).

Além dos impasses institucionais que obriga o governo negociar com a direita no Congresso, não podemos esquecer a influência dos meios de comunicação e dos empresários. O Chile apresenta uma alta concentraçáo dos meios de comunicaçáo nas mãos de poucos grupos (como os grupos Edwards e COPESA que têm o monopólio dos meios impressos). Somado a este fato, o país permitia financiamento privado de campanha ${ }^{18}$, o que possibilitava a influência destes setores no processo de formulação de políticas públicas (RUESCHMEYER, 2004). Segundo Natanson (2009), estes poderes extrainstitucionais, em especial, os de orientação direitista, como o diário $E I$ Mercurio, atrasou uma série de reformas necessárias.

No que se refere as bases sociais, em geral, são desmobilizadas. Isto porque, os partidos passaram a ter uma relaçáo meramente eleitoral com as mesmas. Além disso, o PS, ao longo de sua história, apresentou clara moderação ideológica, aceitando o modelo neoliberal de mercado e se distanciando do movimento sindical, este último débil e fragmentado (POSNER, 2008).

\footnotetext{
${ }^{18}$ Em 2003, houve uma reforma (Lei n. 19.884 e n. 19.885/2003) que estabeleceu mecanismos de financiamento público parcial e um conjunto de regulaçôes para o financiamento privado. Ainda estabeleceu limites para o gasto em campanhas e as normas para doações (BCN, 2003).
} 
O programa de governo (2006-2010) apresentado por Bachelet apontou para a necessidade de reformas legais e políticas educacionais que promovessem a tolerância e a igualdade, reconhecendo que faz falta na política chilena um esforço de prevenção à discriminação (PROGRAMA DE GOBIERNO MICHELLE BACHELET, 2005). Dentre as propostas de Bachelet, no que se refere aos grupos minoritários, estava: a proposta de projeto de lei antidiscriminação; uma política indígena baseada em seu desenvolvimento e identidade; a proposta de um governo paritário entre homens e mulheres nos cargos de designação presidencial e a lei de cotas para corrigir o déficit de representação política feminina.

Bachelet incluiu em sua Agenda Pró Participação a Iniciativa Popular de Lei, enviando o projeto (Boletim 5221-07) para o Congresso em julho de 2007. Dentre os governos concertacionistas, foi único governo a realizar uma proposta concreta sobre o tema. Contudo, a proposta não teve avanços em sua tramitação (VARAS, 2012). Segundo Garretón (2012, p. 149), "todas as propostas de reforma política destinadas a ampliar a participação contaram com oposição da direita que [...] conseguiu impor o voto voluntário e a não participaçấo dos chilenos no estrangeiro".

De acordo com Varas (2012), a participação política tem sido um dos temas mais controvertidos na classe política chilena, sendo vista equivocadamente como uma forma de minimizar o rol das instituiçôes representativas, debilitar os partidos e abrir espaço à instabilidade política. Logo, as reformas institucionais para maior participação, como as eleiçóes de intendentes e conselhos regionais, enfrentaram a reticência dos legisladores a ampliar o espaço de competição eleitoral.

Além das dificuldades com o Congresso, os primeiros anos do governo Bachelet foram marcados por manifestaçóes estudantis (secundaristas), que buscavam mudanças na lei orgânica constitucional herdada da ditadura e na gestão do sistema educacional, além de reivindicar questóes básicas como transporte gratuito e alimentação; pelas manifestaçóes dos trabalhadores subcontratados no setor do cobre e; por manifestaçôes indígenas (povo Mapuche que representa $4 \%$ da população chilena), que reivindicavam a devolução de suas terras ancestrais e a aplicação do Convênio 169 da Organizaçáo Internacional do Trabalho (OIT) (ESCOBAR, 2014). Tais manifestaçóes demonstraram uma certa insatisfaçáo com o governo nos seus dois primeiros anos de mandato. Ademais, as mesmas geraram, entre os opositores do governo e de setores de sua base governamental, uma maior resistência às políticas que buscavam ampliar os canais de participação. A pressão ao governo, segundo 
Garretón (2012), acabou mudando a equipe política de Bachelet, pondo fim a paridade de gênero nos ministérios, uma das inovaçóes democráticas de seu governo.

Bachelet, diante das manifestaçóes, buscou responder às demandas e consolidou um conjunto de políticas públicas e reformas estatais, o que aumentou o seu apoio popular. Mas em geral, as políticas foram pontuais e no processo de discussão, muitas vezes, diversos setores conseguiram atravancar muitas políticas. Um exemplo foi o processo para a reforma trabalhista, em que o governo criou um Conselho Assessor com representação de vários setores empresariais, técnicos, sindicais, intelectuais entre outros. Ao final do processo, ainda que este Conselho tenha apresentado importantes políticas de subsídio, o mesmo não enfrentou a questão da reforma tributária, que sofreu forte oposição da direita, nem conseguiu uma mudança substantiva na legislação trabalhista, bem como não buscou fortalecer os sindicatos (GARRETON, 2012). Bachelet também não conseguiu renovar plenamente os integrantes de seu ministério como havia anunciado, pois diante da correlação de forças dentro da Concertación teve que incorporar dirigentes históricos da coalizão, não necessariamente alinhados integralmente ao seu programa de governo (VARAS, 2012).

O governo Bachelet embora tenha avançado em alguns aspectos como a proteçấo social e, especialmente, na questão de gênero, seu primeiro mandato se caracterizou "por um conservadorismo economicista e tecnocrático, com alguns toques redistributivos" (ESCOBAR, 2014, p. 5). No campo da política internacional, o governo não apostou nos sócios do Mercosul e no fortalecimento da integraçáo regional, o que representou um paradigma distinto de política internacional, quando comparado ao Brasil e à Venezuela, pois priorizou os acordos bilaterais com os Estados Unidos. Ao final do governo, Bachelet contava com alta popularidade, mas esta não reverteu em votos para o candidato de sua coalizão Eduardo Frei ${ }^{19}$ (PDC) nas eleiçôes de 2009/201020. A Concertación havia fracassado. Já internamente a mesma estava desgastada, com uma série de cisóes, bem como com a saída de figuras importantes dos partidos da coalizão, como a de Marco Enríquez-Ominami que era do PS e, ao ser impedido de participar das primárias da coalizão para a escolha do

\footnotetext{
${ }^{19}$ Vale lembrar que no Chile não há reeleição consecutiva.

${ }^{20}$ Nas eleiçôes de 2009, os candidatos mais votados foram o candidato de centro-direita Sebatian Pińera com 44\% dos votos e o candidato da base governista Eduardo Frei com 29,6\% dos votos. Como nenhum dos candidatos à presidência obtiveram maioria absoluta dos votos, houve o segundo turno em 17 de janeiro de 2010 entre os dois candidatos mais votados. Pińera saiu vitorioso com $51,61 \%$ dos votos contra 48,39\% de Eduardo Frei.
} 
candidato a presidente, saiu do partido e candidatou-se para as eleiçóes presidenciais de 2009 como candidato independente, obtendo significativos $20 \%$ dos votos. O fato é que a Concertación diante das divergências internas se configurou em mais um impasse ao governo Bachelet.

A análise que se faz dos governos da centro-esquerda durante vinte anos no poder (1990-2010) é que os mesmos buscaram melhorar o modelo, porém, cuidando sempre para não "chutar o tabuleiro" (NATANSON, 2009, e-book, posiçáo 2573). Não romper com os legados institucionais da ditadura de Pinochet custou caro à democracia chilena, caracterizada por restriçóes à soberania popular; limites das opçóes políticas por mecanismos de mercado; imagem do pluralismo sem alterar as relaçóes tradicionais de poder; desenho equivocado de arranjos institucionais; e sociedade civil fragmentada incapaz de gerar legitimidade ou consenso social (WHITEHEAD, 1993).

Como afirma Garretón (1992), o Chile não completou o seu processo de transição e isto se deve à ausência de reformas institucionais, que não foram possíveis devido aos limites impostos, principalmente pela presença da Constituição de 1980 e aos pactos estabelecidos tanto com a oposiçáo quanto internamente entre os partidos da coalizáo Concertación. Embora, tais pactos tenham mantido certa estabilidade democrática, a democracia chilena ficou restrita aos procedimentos e a esquerda limitada pelos pactos de estabilidade.

Como afirma Karl (1988, p. 300), "uma democracia implantada via pacto pode institucionalizar uma tendência conservadora no campo político, criando um novo status quo capaz de bloquear um maior progresso na direçáo de uma democracia política, social e econômica". O caso chileno, ainda que tenha alcançado uma "democracia estável", "essa conquista não desprezível parece envolver sérios custos em termos de igualdade social e econômica” (O’DONNELL, 1988, p. 25).

Se o custo da "democracia pactuada" é que a mesma se restrinja à democracia procedimental, no limite, esta, também pode limitar o ideal da esquerda no poder, tal como a implementação de inovaçôes democráticas. Isto porque, os valores e os fins da democracia geralmente ficam subordinados aos acordos políticos de governabilidade e da conservação do sistema. 


\section{Considerações Finais}

O objetivo deste artigo consistiu em analisar se o governo de Michelle Bachelet em seu primeiro mandato (2006-2010) conseguiu aprofundar a democracia chilena a partir de inovaçóes democráticas. A especificidade do caso chileno tem como fatores explicativos o formato da transição para a democracia, através de pactos e coalizóes, bem como a presença de entraves autoritários deixados pela ditadura de Pinochet e não superados pelos governos concertacionistas.

O pacto de governabilidade estabelecido com a direita no processo de transição para a democracia e a formação de uma coalizão - Concertación - da qual o PS fez parte, impôs ao governo a conciliação de diversos interesses divergentes que, em alguns casos, o limitou no processo de implementação de políticas públicas. Ademais, da influência de setores econômicos e de setores da igreja na formulação da agenda do governo.

Os entraves autoritários - com um sistema eleitoral binominal que tem como tendência distorcer a representação, o quórum alto para implementar reformas constitucionais e a presença de uma Constituição extremamente restritiva somados a uma base social débil, devido ao distanciamento dos partidos (inclusive do PS) com relação à sociedade - dificultaram o governo de Bachelet na implementação de seu plano de governo.

Assim, os limites impostos - pela correlação de forças com a direita, pelos pactos e pelos legados institucionais - ao governo Bachelet não permitiram a mudança da Constituição de 1980, herdada da ditadura, e nem mesmo reformas significativas a ela. A implicação da manutenção dessa carta magna está na restrição à soberania popular. Sem mecanismos de democracia direta, como consultas populares (para além das eleiçóes tradicionais) e iniciativas populares, o governo não conseguiu aprofundar a democracia chilena. No que se refere à representatividade dos grupos minoritários, como mulheres e indígenas, o governo buscou avançar ao estabelecer a paridade entre homens e mulheres nos ministérios, porém, como essa medida não foi institucionalizada o retrocesso foi visível no governo seguinte de Sebastian Piñera (2010-2014).

Esta análise nos permite afirmar que o primeiro governo Bachelet apresentou baixa capacidade na condução das políticas públicas e na implementação de mudanças institucionais, pois estava atado às instituiçóes restritivas, como a Constituição de 1980, o sistema binominal e o quórum alto para reformas, bem como, aos pactos políticos e aos interesses dos setores econômicos. Logo, a correlação de forças e os recursos políticos presentes no governo Bachelet em seu primeiro 
mandato (2006-2010) criou impasses às possíveis inovações democráticas, condicionando-o a um "governo de continuidades", com a manutenção da lógica de uma democracia liberal em seu sentido minimalista, em que a soberania popular está restrita à arena eleitoral.

Kátia Alves Fukushima é Doutora em Ciência Política pela Universidade Federal de São Carlos - UFSCar; Membro do Núcleo de Estudos dos Partidos Políticos Latino-americanos (NEPPLA) da UFSCar e Professora do Instituto Federal de São Paulo (IFSP Sertãozinho). E-mail: katia_alves1981@yahoo.com.br.

\section{Referências}

ALTMAN, David. Continuidades, Cambios y Desafíos Democráticos en Chile (2006-2009). Colombia Internacional, s/v., n. 64, p. 12-33, 2006.

ALTMAN, David; AGUERO, Soledad; SALAS, Valentina. Municipalidades, ciudadanos y democracia directa en Chile: esbozos de una relación fluida. In: LISSIDINI, Alicia (org.). Democracias en Movimiento. Mecanismos de democracia directa y participativa en América Latina. México: Universidad Nacional Autónoma de México, 2014.

ANGELL, Alan. A esquerda na América Latina após C.1920. In: BETHELL, Leslie (org.). História da América Latina: A América Latina pós 1930: Estado e Política. São Paulo: EDUSP, 2009. p. 471546.

BCN. Biblioteca del Congreso Nacional de Chile. Ley número 19.884 e Ley número 19.885, 2003. Disponível em: <http://www.leychile.cl>. Acesso em: 28 jul. 2016.

BLOFIELD, Merike. The politics of moral sin: Abortion and divorce in Spain, Chile and Argentina, Routledge, v. 51, n. 2, 2006.

BOENINGER, Edgardo. La visión política del sistema electoral chileno. In: FONTAINE, Arturo (org.). Reforma del sistema electoral chileno. PNUD, Centro de Estudios Públicos (CEP), Proyectamérica, CIEPLAN, 2009. p. 167-175.

CASAS, Juan Carlos. Um novo caminho para a América Latina. Rio de Janeiro: Record, 1993. 
CASTELLS, Manuel. Globalización, desarrollo y democracia: Chile en el contexto mundial. Santiago: Fondo de Cultura Económica, 2005.

CHILE. Constitución. Constitución Política de la República de Chile. Biblioteca del Congreso Nacional de Chile, 1980.

Ley número 18.948. Ley Organica Constitucional de las Fuerzas Armadas. Publicada no Diário Oficial em 22 fev. 1990. Disponível em: <http://www.leychile.cl/Navegar?idNorma=30318>. Acesso em: 26 jan. 2017.

Ley número 20.840. Substituye el sistema electoral binominal por uno de carácter proporcional incluso y fortalece la representatividad del Congreso Nacional. Publicada no Diário Oficial em 05 maio 2015. Disponível em: <http://www.leychile.cl/Navegar?idNorma=1077039>. Acesso em: 26 jan. 2017.

CONTRERAS NATERA, Miguel Ángel. Entre la altermodernidad y la gobernanza global. Neoliberalismo interrumpido en América Latina. Summer LASAK International Conference. Korean Association of Luso-Brazilian Studies and Institute of Iberoamerican Studies, BUFS, Coreia, 2014.

DAGNINO, Evelina; OLVERA, Alberto; PANFICHI, Aldo. Para uma leitura da disputa pela construção democrática na América Latina. In: DAGNINO, Evelina; OLVERA. Alberto; PANFICHI, Aldo (orgs). A Disputa pela Construção Democrática na América Latina. São Paulo: Paz e Terra, Unicamp, 2006. p. 13-91.

DOSEK, Tomás. Chile: elecciones presidenciales y legislativas (1989-2010). Proyecto OIR, Instituto de Iberoamérica. Universidad de Salamanca, 2010. Disponível em: <http://americo.usal.es/oir/opal/elecciones/Elecc_Chile_tomas_dosek.pdf>. Acesso em: 26 jan. 2018.

EASTON, David. Política Moderna: un estudio sobre la situación de la ciencia política. D.F.: Editorial Letras, S.A, 1968.

EMOL. Composición del Congreso. Senadores. Especiales, 2009. Disponível em: <http://www.emol.com/especiales/2009/nacional/presidenciales2009/congreso.asp>. Acesso em: 09 abr. 2018.

ESCOBAR, Luis Eduardo. Michelle Bachelet en busca de la transformación de Chile. Nueva Sociedad, s/v., n. 252, p. 4-14, julio-agosto, 2014.

FIORI, José Luís da C. Olhando para a esquerda. Economia Política Internacional: Análise Estratégica, s/v., n. 9, p. 1-23, julho/dezembro, 2006.

FUENTES, Claudio. La transición auto-contenida: Elites políticas y reformas constitucionales en Chile (1990-2010). In: XXIX Latin American Studies Association Congress (LASA), Canadá, 6-9 out. 2010.

GARCIA, Marco Aurélio. Nuevos gobiernos en América del Sur. Del destino a la construcción de un futuro. Nueva Sociedad, s/v., n. 217, p. 118-126, 2008.

GARRETÓN, Manuel Antônio. A Redemocratização no Chile: transição, inauguração e evolução. Lua Nova, s/v., n. 27, p. 59-92, 1992. Disponível em: <http://www.scielo.br/pdf/ln/n27/a04n27.pdf>. Acesso em: 26 jan. 2018.

GARRETÓN, Manuel Antônio. Neoliberalismo corregido y progresismo limitado: los gobiernos de la Concertación em Chile 1990-2010. Chile: ARCIS; CLACSO, 2012. 
HOROCHOVSKI, Rodrigo Rossi; MEIRELLES, Giselle. Problematizando o conceito de empoderamento. In: Anais do II Seminário Nacional Movimentos Sociais, Participaçáo e Democracia. UFSC: Florianópolis, Brasil, 25 a 27 de abril de 2007.

KARL, Terry Lynn. El petróleo y los pactos políticos: la transición a la democracia en Venezuela. In: O'DONNELL, Guillermo; SCHMITTER, Philippe C.; WHITEHEAD, Laurence (Orgs.). Transiciones desde un gobierno autoritario. América Latina. v. 2. Paidós, 1988.

LINZ, Juan; STEPAN, Alfred. A transiçâo e consolidação da democracia. A experiência do Sul da Europa e da América do Sul. São Paulo: Paz e Terra, 1999.

LINZ, Juan. La Quiebra de las Democracias. Madrid: Alianza Editorial, 1987.

LISSIDINI, Alicia. Democracia directa en Latinoamerica: Entre la delegación y la participación. $1^{\text {a }}$ ed. Buenos Aires: Consejo Latinoamericano de Ciencias Sociales - CLACSO, 2011.

MARTINS, Renato. Chile: A democracia e os limites do consenso. Lua Nova, s/v., n. 49, p. 65-86, 2000.

MONIZ BANDEIRA, Luiz Alberto. Fórmula para o caos. Ascensão e queda de Salvador Allende (1970-1973). Rio de Janeiro: Civilizaçáo Brasileira, 2008.

MOREIRA, Constanza. Izquierda, partidos y gobiernos en el Cono Sur. In: QUIROGA, Yesko; ENSIGNIA, Jaime (orgs.). Renovación partidaria: Los partidos políticos progresistas en los países del Cono Sur. Fundación Friedrich Ebert, 2009. p. 13-31.

NATANSON, José. La nueva izquierda. Triunfos y derrotas de los gobiernos de Argentina, Brasil, Bolivia, Venezuela, Chile, Uruguay y Ecuador. Buenos Aires: Debate, 2009.

NEGRETTO, Gabriel. Procesos Constituyentes y Refundación Democrática. El Caso de Chile en Perspectiva Comparada. Revista de Ciencia Política, v. 35, n. 1, p. 201-215, 2015.

O’DONNELL, Guillermo. Introdução a los casos latino-americanos. In: O'DONNELL, Guillermo; SCHMITTER, Philippe C.; WHITEHEAD, Laurence (Orgs.). Transiciones desde un gobierno autoritario. América Latina. v. 2. Paidós, 1988.

PAYNE, Mark. Sistemas de elección legislativa y gobernabilidad democrática. In: PAYNE, Mark; ZOVATTO, Daniel; MATEO DÍAZ, Mercedes (orgs.). La política importa: democracia y desarrollo en América Latina. Washington, D.C.: Banco Interamericano de Desarrollo, 2006. p. 4189.

POSNER, Paul W. State, market, and democracy in Chile: the constraint of popular Participation, Palgrave MacMillan, 2008.

PROGRAMA DE GOBIERNO MICHELLE BACHELET. Estoy contigo, 2006-2010. 15 de octubre de 2005.

PS. Partido Socialista de Chile. Reseña Histórica. Archivo Parlamentario Salvador Allende, 2004. Disponível em: <http://web.pschile.cl/npschile/index.php/ps-chile/resena-historica>. Acesso em: 12 jan. 2016.

QUILODRÁN, Federico. Aprobaron en Chile la ley de divorcio. La Nacion: El Mundo. 12 de marzo de 2004. Disponível em: <http://www.lanacion.com.ar/580679-aprobaron-en-chile-la-ley-dedivorcio>. Acesso em: 28 jul. 2016.

RUESCHMEYER, Dietrich. The Quality of Democracy: Addressing Inequality. Journal of Democracy, v. 15, n. 4, p. 76-90, 2004. 
36 | Kátia Alves Fukushima

SERVEL. Servicio Electoral República de Chile. Elección de diputados 2005. Disponível em: <http://historico.servel.cl/SitioHistorico/index2005_dipu.htm>. Acesso em: 09 abr. 2018.

TOURAINE, Alain. Entre Bachelet y Morales: existe una izquierda en América Latina. Nueva Sociedad, s/v., n. 205, p. 46-55, 2006.

VARAS, Augusto. La democracia frente al poder. Chile 1990-2010. Santiago de Chile: Catalonia, 2012.

WEYLAND, Kurt. Os riscos na reestruturação econômica da América Latina: liçôes da teoria prospectiva. Opinião Pública, v. 6, n. 1, p.76-108, 2000.

WHITEHEAD, Laurence. The alternatives to 'liberal democracy': A Latin American Perspective. In: HELD, David (org.). Prospects for democracy. North South East West. Stanford University Press, 1993.

Texto recebido em 28 de janeiro de 2018. Aprovado em 12 de março de 2018. 